\title{
Apparatus that separated radiotherapy from radiology
}

\author{
Dr KY Cheung, MHKCR
}

Education and Research Committee, Hong Kong Museum of Medical Sciences Society

https://doi.org/10.12809/hkmj-hkmms202102

\section{First $\mathrm{X}$-ray machine in Hong Kong}

The earliest recorded clinical use of X-ray in Hong Kong was at the Alice Ho Miu Ling Nethersole Hospital, in May 1910., The X-ray machine was called a 'Roentgen Ray Apparatus' at that time, 15 years after the discovery of X-rays by German physicist Wilhelm Conrad Roentgen. Radiation doses received by patients were not measured in those days because the methodology and instrumentation for quantifying roentgen radiation had yet to be developed, although the possibility of using photographic plates and electrical conductivity in air had been proposed by Ernest Rutherford in 1899. ${ }^{3}$ Patient dosimetry was primarily based on the exposure time and the effects of radiation such as skin reaction at the treatment site. Radiation measurements and hence patient dosimetry became a reality in 1928 when the unit of X-ray radiation, the roentgen, was defined and suitable instrumentations became available. ${ }^{3}$

\section{Radiotherapy at its embryonic stage}

Public radiology services in Hong Kong started in around 1929 at the Government Civil Hospital, which later became Sai Ying Pun Hospital. ${ }^{4}$ In the early 1930s, diagnostic X-ray machines were used by radiologists for the treatment of skin cancers, and radium tubes were used by gynaecologists for treatment of carcinoma of the uterine cervix. ${ }^{4}$ One of the problems with using diagnostic X-ray machines for skin cancer treatments was that a long X-ray target-to-skin distance had to be used for electrical safety. As a result, the dose rate at the skin was too low for practical and efficient treatment delivery. ${ }^{5}$ Radium radiotherapy also had limitations, primarily that radium was in short supply and it was expensive. Specially designed X-ray radiotherapy machines, such as the Chaoul contact therapy X-ray machine, were developed to address these issues. Dedicated radiotherapy equipment for cancer treatment was not available in Hong Kong until 30 June 1937 when Queen Mary Hospital opened. The new hospital had a range of radiotherapy facilities, including a Chaoul contact therapy X-ray machine, a General Electric (GE) ST-150 superficial X-ray therapy machine, and some radium tubes. In those days, radiotherapy and diagnostic radiology services were operated under the Radiological Sub-Department. The specialist in charge of the sub-department was Dr FJ Farr, ${ }^{6}$ from the UK. He was assisted by two radiographers also from the UK, and four local radiographic assistants. Later, in 1939, a GE Maxima $400 \mathrm{kV}$ deep X-ray therapy machine was added to the department for treating deep-seated cancer diseases. Dr Farr effectively planted the seed for radiotherapy service before his retirement in 1950 and he was succeeded by Professor HC Ho. ${ }^{6}$ Professor Ho added a Bryant Simmons $18 \mathrm{Ci}$ Cobalt-60 teletherapy machine in 1953 (the Cobalt source was replaced by a 60Ci source in 1958) and a GE Maxitron $250 \mathrm{kV}$ deep X-ray therapy machine in 1958. Thus, Professor Ho created a solid foundation for his pioneering work in radiation therapy and paved the way for the development of the radiation oncology subspecialty in Hong Kong.

\section{Chaoul contact therapy X-ray machine}

Installation of the Chaoul contact therapy X-ray machine in 1937, together with other radiotherapy facilities, marked the beginning of external beam radiation therapy in Hong Kong. The Chaoul machine, which was manufactured by Siemens in Erlangen, Germany, was developed by German radiologist Professor Henri Chaoul in the early $1930 \mathrm{~s}^{7,8}$ It was designed to replace or provide an alternative to radium therapy in the treatment of cancers in the skin, rectum, cervix, and oral cavity. As reported by Chaoul at the Royal Society of Medicine on 21 February $1936,{ }^{8}$ no country possessed sufficient radium to treat all patients requiring treatment. The contact X-ray therapy apparatus he developed made it possible to treat all suitable cases more cheaply, making the technology more accessible internationally. The machine operated at a constant potential of $60 \mathrm{kV}$ and an anode current of $4 \mathrm{~mA} .5,8$ The X-ray tube had a heated filament, a hollow anode, and a water-cooled transmission-type X-ray target located at the end of the long hollow anode tube. Electrons could be directed to pass down the hollow anode cylindrical tube to strike a target at the end of the tube (also serve as treatment applicator) 
to produce X-rays for contact or short-distance treatment. The target was electrically grounded so that the X-ray target-to-skin distance could be very short. Treatment applicators could be inserted onto the applicator to define the treatment area and target-to-skin distance. The output exposure rate reported was about $150 \mathrm{r} / \mathrm{min}$ at a target-toskin distance of $5 \mathrm{~cm}$ and the treatment field size (9-25 $\left.\mathrm{cm}^{2}\right)$ was selectable. ${ }^{6}$ The output exposure of an X-ray machine at that time was measured in roentgen " $r$ ", which was a measure of the amount of ionisation the radiation produced in $1 \mathrm{cc}$ of air. The symbol " $r$ " was replaced by " $R$ " for absorbed dose in tissue, and "rad" was adopted for dose calibration in the 1960s. The Chaoul X-ray machine was replaced in 1958 by a Philips contact therapy X-ray machine. The Chaoul X-ray tube, which is a treasure for the radiotherapy community and has been maintained in excellent condition, was donated by the Hong Kong College of Radiologists (HKCR) to the Hong Kong Museum of Medical Sciences (Fig 1).

\section{General Electric Maxima 400 kV deep $X$-ray therapy machine}

The GE Maxima, made in the United States, was the first deep X-ray (also known as orthovoltage) therapy machine installed in Hong Kong. It was installed by a local GE engineer Mr Raymond Huang in 1938 and commissioned for clinical use in 1939.6 The machine operated at an anode voltage up to $400 \mathrm{kV}$. To operate at such a high potential, the X-ray tube was housed inside a large tank filled with insulation oil to prevent electrical breakdown and allow tube cooling. The high-voltage generator was powered by a resonant transformer which was also fitted inside the oil tank (Fig 2a). Initial operation of the GE Maxima and other radiotherapy machines for patient treatment was carried out by the radiology specialists Dr Farr and Dr Ho until the early 1950s when the task was assigned to radiographers who returned to Hong Kong after completing their therapy training in the UK. Radiation output of the therapy machines was measured by these radiographers until 1956, when Mr GF Mauldon took up the task. Mr Mauldon was an Australian medical physicist trained at the Peter MacCallum Clinic in Melbourne, and he joined the Radiological Sub-Department on a 2-year secondment arrangement. Around 1964, the GE Maxima was relocated to a newly built large centre, the Royal Hong Kong Jockey Club Institute of Radiology and Oncology at Queen Elizabeth Hospital. The GE Maxima became functionally obsolete and was removed from patient service when state-of-the-art megavoltage radiotherapy technologies were installed at the Institute, including two linear accelerators and a Betatron. However, the GE Maxima remained onsite in the Institute until its decommissioning in the late 1980s. The 1.4-m-long $\mathrm{X}$-ray tube has been kept and is currently on display at the Department of Radiation Oncology at Queen Elizabeth Hospital (Fig 2b).

\section{General Electric Maxitron 250 kV deep $\mathrm{X}$-ray therapy machine}

The GE Maxitron $250 \mathrm{kV}$ deep X-ray therapy machine, also made in the United States, was installed at Queen Mary Hospital in 1958 for treatment of deep-seated internal diseases. It was

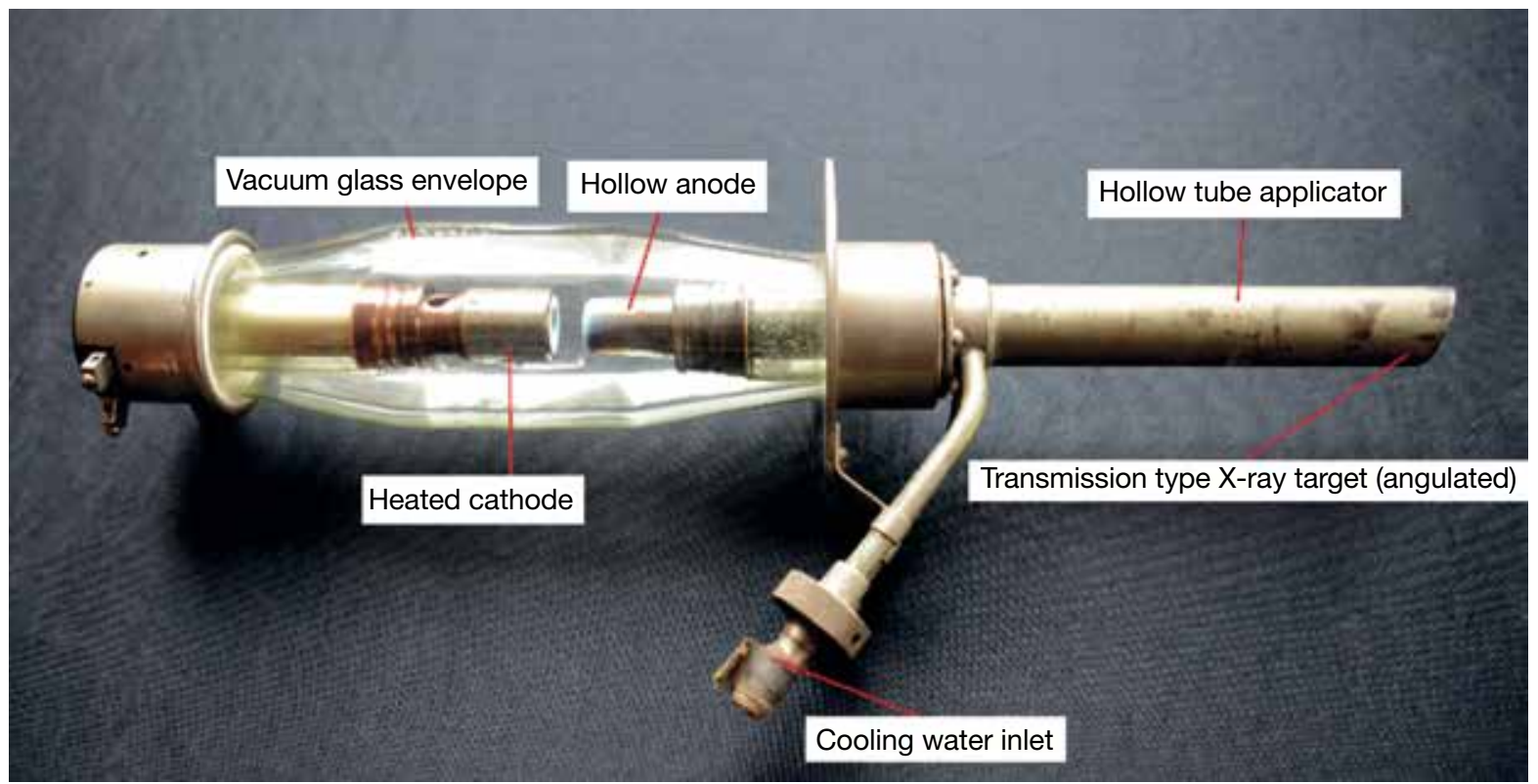

FIG I. Photograph of the Chaoul contact therapy X-ray tube 


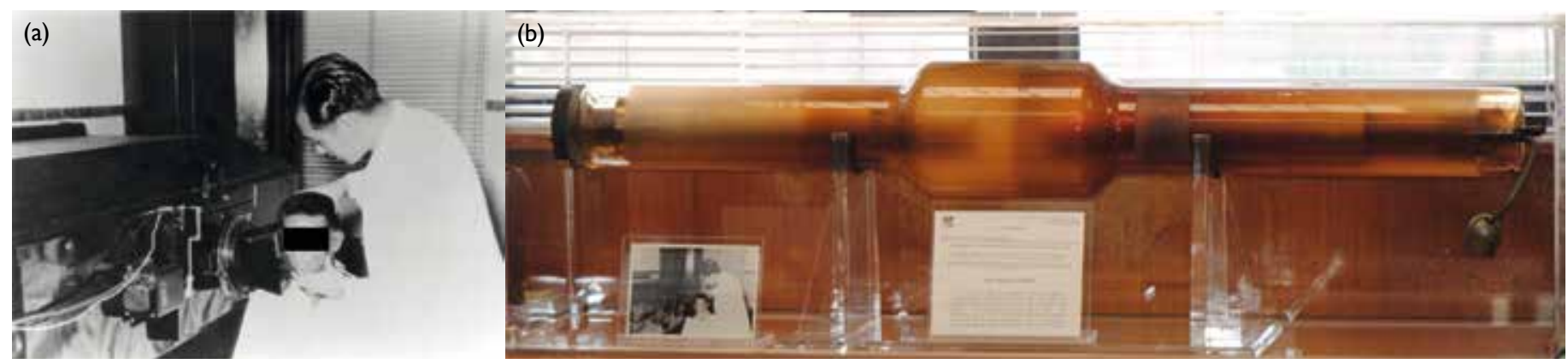

FIG 2. (a) Black-and-white photograph of a patient being setup for treatment by the GE Maxima $400 \mathrm{kV}$ deep X-ray machine (courtesy of Mr GF Mauldon). (b) Photograph showing the large GE Maxima-400 X-ray tube (courtesy of Dr CK Law)

an advanced treatment machine at the time with a relatively sophisticated treatment control unit that had a roentgen meter and timer for treatment control. The machine came with a dedicated treatment table, a set of treatment applicators, beam hardening filters, and related accessories, including intracavitary treatment applicators. The treatment head had a light projector simulating the X-ray beam and a mechanical distance pointer for guiding the positioning of the patient for treatment delivery. The $\mathrm{X}$-ray tube (Fig 3) was air-cooled and it could operate up to $250 \mathrm{kV}$ with an anode current of up to $30 \mathrm{~mA}$ to deliver a radiation output of $75 \mathrm{r} / \mathrm{min}$ at $50 \mathrm{~cm}$ target-to-skin distance using a 2-mm copper filter. The GE Maxitron X-ray tube was donated to the Museum by the HKCR.

\section{Philips Metalix contact X-ray therapy machine}

The Chaoul contact therapy X-ray machine was replaced by a Philips Metalix contact therapy machine in 1958. The Philips Metalix, made in Eindhoven, the Netherlands, had a similar design and operation to the Chaoul machine. It was a mobile unit with a constant potential generator and control unit on wheels (Fig 4a). The X-ray tube had a similar design to that of the Chaoul tube, except that the Philips tube was air-cooled (Fig 4b). The Philips Metalix operated at $50 \mathrm{kV}$, anode current at $2 \mathrm{~mA}$, maximum field size of $5 \mathrm{~cm}^{2}$, and an exposure rate of up to $10000 \mathrm{r} / \mathrm{min}$. The Philips Metalix X-ray tube was also donated to the Museum by the HKCR.

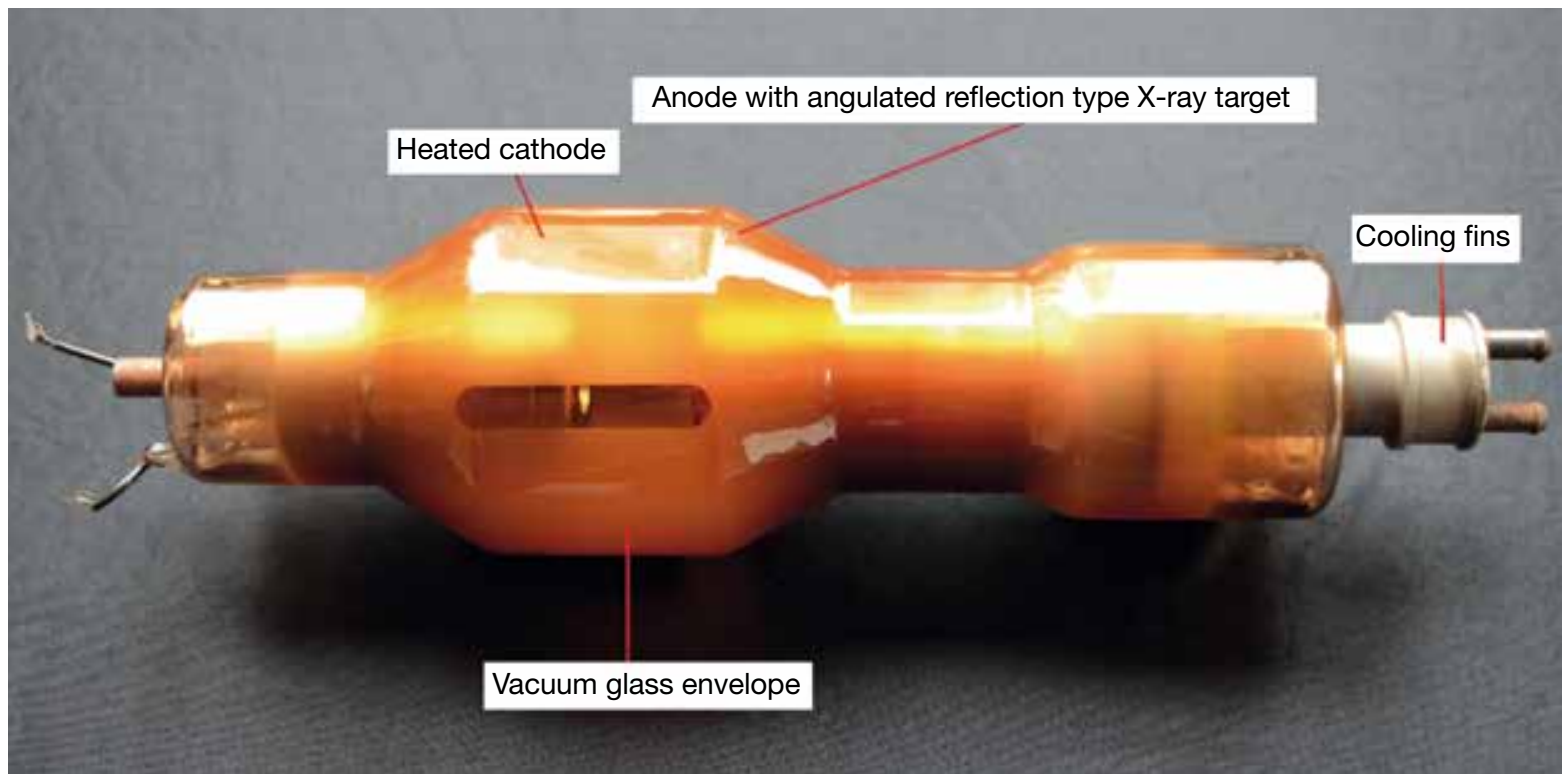

FIG 3. GE Maxitron $250 \mathrm{kV}$ deep X-ray tube 


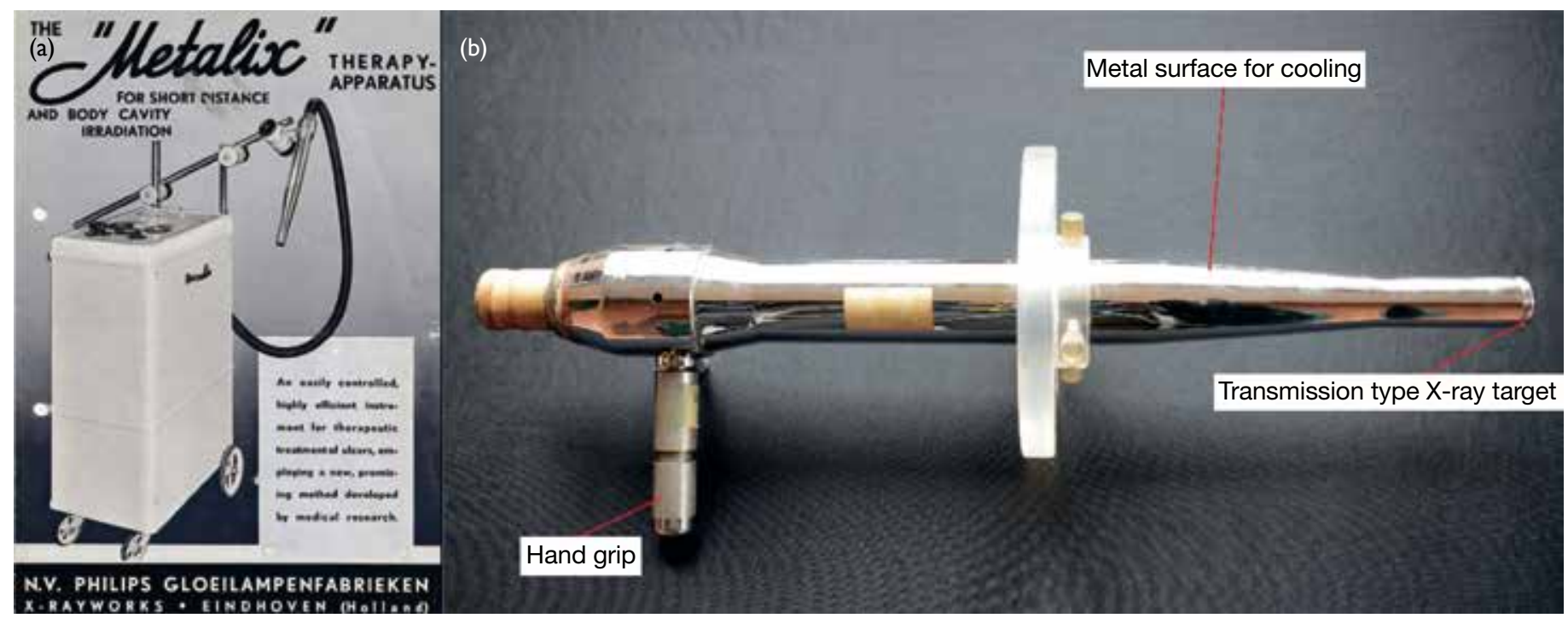

FIG 4. (a) Image from a product catalogue of a Philips Metalix contact therapy machine (courtesy of Philips Electronics Hong Kong Limited).

(b) Photograph of the Philips Metalix contact therapy X-ray tube

\section{Acknowledgements}

The author would like to thank Dr CK Law, President of Hong Kong College of Radiologists for reviewing this manuscript and sharing his photos on historical radiotherapy equipment; $\mathrm{Mr}$ GF Mauldon for sharing his archive of photos and documents on the history of medical physics and radiology in Hong Kong; and Mr Dominick Yim of Philips Electronics Hong Kong Limited for provision of a copy of the original product catalogue on the Philips Metalix contact therapy machine.

\section{References}

1. Paterson EH. A hospital for Hong Kong: The Centenary History of the Alice Ho Miu Ling Nethersole Hospital. Hong Kong: Alice Ho Miu Ling Nethersole Hospital; 1987.

2. Luk SY. The mobile X-ray machine. Hong Kong Med J 2016;22:194-5.

3. Almond PR. A historical perspective: a brief history of dosimetry, calibration protocols, and the need for accuracy. In: Rogers DW, Cygler JE, editors. Clinical Dosimetry Measurements in Radiotherapy. Madison, Wisconsin; Medical Physics Publishing: 2009; 1-28.

4. Ram V. Emperor Extraordinaire: Life and Work of John HC Ho. Hong Kong: Scientific Communications (HK) Limited; 2003.

5. Pendergrass PE, Hodes PJ, Garrahan CJ. Roentgen therapy by the method of Chaoul. Radiology 1939;32:142-54.

6. Ho JH, Mauldon GF, Huang DP, Kwan HC. Development of radiation oncology in Hong Kong up to 1985. Int J Radiat Oncol Biol Phys 1997;37:125-9.

7. Kuttig H. Die klinischen Applikationsverfahren zur Erzielung einer geeigneten räumlichen Dosisverteilung [in German]. In: Scherer E, editor. Strahlentherapie. Springer, Berlin, Heidelberg; 1976: 77-104.

8. Short-distance low-voltage X-ray therapy: (Section of Radiology). Proc R Soc Med 1936;29:791-808. 